\title{
NATURAL COLLOIDS ARE THE DOMINANT FACTOR IN THE SEDIMENTATION OF NANOPARTICLES
}

\author{
Joris T.K. Quik, $* \dagger \ddagger$ Martien Cohen Stuart, $§$ Marja Wouterse, $\ddagger$ Willie Peijnenburg, $\ddagger \|$ \\ A. Jan Hendriks, $\dagger$ and Dik van de MeEnT $\dagger$ \\ $\dagger$ Institute for Wetland and Water Research, Department of Environmental Science, Radboud University Nijmegen, Nijmegen, The Netherlands \\ $\ddagger$ Laboratory for Ecological Risk Assessment, National Institute for Public Health and the Environment, Bilthoven, The Netherlands \\ $\S$ Laboratory of Physical Chemistry and Colloid Science, Wageningen University and Research Centre, Wageningen, The Netherlands \\ \|Institute of Environmental Sciences, Faculty of Science, Leiden University, Leiden, The Netherlands
}

(Submitted 25 August 2011; Returned for Revision 13 October 2011; Accepted 14 December 2011)

\begin{abstract}
Estimating the environmental exposure to manufactured nanomaterials is part of risk assessment. Because nanoparticles aggregate with each other (homoaggregation) and with other particles (heteroaggregation), the main route of the removal of most nanoparticles from water is aggregation, followed by sedimentation. The authors used water samples from two rivers in Europe, the Rhine and the Meuse. To distinguish between small (mainly natural organic matter [NOM]) particles and the remainder of the natural colloids present, both filtered and unfiltered river water was used to prepare the particle suspensions. The results show that the removal of nanoparticles from natural river water follows first-order kinetics toward a residual concentration. This was measured in river water with less than $1 \mathrm{mg} \mathrm{L}^{-1} \mathrm{CeO}_{2}$ nanoparticles. The authors inferred that the heteroaggregation with or deposition onto the solid fraction of natural colloids was the main mechanism causing sedimentation in relation to homoaggregation. In contrast, the NOM fraction in filtered river water stabilized the residual nanoparticles against further sedimentation for up to $12 \mathrm{~d}$. In $10 \mathrm{mg} \mathrm{L}^{-1}$ and $100 \mathrm{mg} \mathrm{L}^{-1} \mathrm{CeO}_{2}$ nanoparticle suspensions, homoaggregation is likely the main mechanism leading to sedimentation. The proposed model could form the basis for improved exposure assessment for nanomaterials. Environ. Toxicol. Chem. 2012;31:1019-1022. (C) 2012 SETAC
\end{abstract}

Keywords-Nanoparticles Natural colloids Sedimentation Modeling Exposure concentration

\section{INTRODUCTION}

The large-scale production of nanomaterials [1] has raised concerns about their potential environmental risks [2]. Typical colloidal processes need to be taken into account when estimating the exposure concentration of nanomaterials [3-5]. Although individual colloidal processes such as aggregation and sedimentation have been studied to a reasonable extent, this is usually done only with well-defined model systems, which lack the complexity present in the natural environment [6,7]. In the present study, we investigate the effect of natural colloids on the sedimentation of $\mathrm{CeO}_{2}$ nanoparticles in river water.

Natural colloids are a ubiquitous component of natural surface water and are likely to affect the fate of nanoparticles $[3,8,9]$. Natural colloids are generally categorized into three main components [10]: inorganic solids, small organic compounds (a few nanometers), and larger, rigid biopolymers $(0.1-1 \mu \mathrm{m})$. The interaction of nanoparticles with the full range of natural colloids has been studied poorly, and most studies have emphasized the natural organic matter (NOM) fraction, which consists of relatively small organic compounds, such as fulvic and humic acids [11-15]. However, several studies have shown that nanoparticles tend to associate with biofilms $[16,17]$ and wastewater biomass $[18,19]$, indicating that heteroaggregation and deposition are important aspects of the fate of nanoparticles in the aquatic environment [6].

All Supplemental Data may be found in the online version of this article.

* To whom correspondence may be addressed (joris.quik@wur.nl).

Published online 23 February 2012 in Wiley Online Library (wileyonlinelibrary.com)
Estimating the exposure concentration of nanoparticles requires a quantitative model describing the removal processes in the water phase. We previously proposed to use first-order rate constants for this [4]. This suggestion is based on the assumption that first-order kinetics apply when heteroaggregation with or deposition onto natural colloids is the dominant process affecting aggregation and sedimentation. We use the sedimentation data of $\mathrm{CeO}_{2}$ nanoparticles in natural river water to test our proposed model. This model describes the removal of nanoparticles by first-order kinetics toward a residual concentration in the water phase. This is the first time such a model could be verified by experimental data.

\section{MATERIALS AND METHODS}

\section{Sampling and sedimentation}

River water was sampled at the Dutch water monitoring pontoons in Eijsden (Meuse) and Lobith (Rhine), The Netherlands. The samples were stored at $4{ }^{\circ} \mathrm{C}$, and the experiments were started on the day after sample collection. Before suspension preparation, the river water was shaken to resuspend any sedimented natural colloids, and a portion of the river water was filtered over $0.2-\mu \mathrm{m}$ Pall nuclepore filters as pretreatment. The suspensions were prepared by adding different doses of $\mathrm{CeO}_{2}$ nanoparticles to $100 \mathrm{ml}$ river water to reach 1,10 , and $100 \mathrm{mg} \mathrm{L}^{-1}$ mass concentrations of $\mathrm{CeO}_{2}$, respectively. The sedimentation behavior was followed for $12 \mathrm{~d}$ by sampling the supernatant (Fig. 1). Samples from the supernatant were taken at six different time points during the experiment at $3 \mathrm{~cm}$ above the bottom of the glass flasks, and the total height of the water column was $6 \mathrm{~cm}$ (Fig. 1). This method was adapted from two 


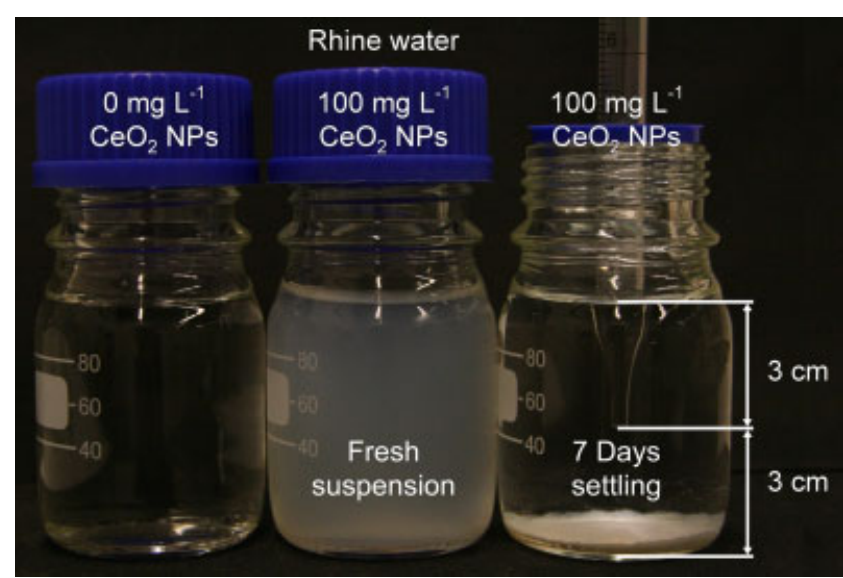

Fig. 1. Experimental setup showing particle suspensions that were left to settle for $12 \mathrm{~d}$ in flasks. At set time points, a sample of the supernatant was collected for analysis at $3 \mathrm{~cm}$ above the bottom of the flask. [Color figure can be seen in the online version of this article, available at wileyonlinelibrary.com.]

previous studies describing the stabilizing effect of NOM $[11,13]$.

\section{Nanoparticles and analysis}

The $\mathrm{CeO}_{2}$ nanoparticles were obtained as a $100 \mathrm{~g} \mathrm{~L}^{-1}$ suspension at $\mathrm{pH} 4$ (kindly supplied by Umicore Ltd., as part of the NanoInteract project). The particles were dried after synthesis and redispersed into Milli-Q water by ball milling. Prior to the redispersion, the $\mathrm{pH}$ of the Milli-Q water was adjusted to 4 using diluted nitric acid. The manufacturer reported a BranauerEmmett-Teller (BET) surface area of $42 \mathrm{~m}^{2} \mathrm{~g}^{-1}$ and a calculated BET surface-based particle diameter of $20 \mathrm{~nm}$. The $\mathrm{CeO}_{2}$ particles have an isoelectric point at $\mathrm{pH} 8.0$ [13,20,21].

The measurements of the water quality parameters were obtained from the freely accessible waterbase application [22] (see Supplemental Data, Table S1). The concentration of suspended solids was measured by filtering with $1.2-\mu \mathrm{m}$ Whatman $\mathrm{GF} / \mathrm{C}$ filters and weighing after drying. The concentration of $\mathrm{CeO}_{2}$ nanoparticles was measured by high-resolution inductively coupled plasma-mass spectroscopy (Element 2 HR-ICPMS; Thermo). Before analysis, $4 \mathrm{ml}$ of the sample was weighed into $50-\mathrm{ml}$ tubes for digestion with $7 \mathrm{ml} 14.4 \mathrm{M} \mathrm{HNO}_{3}$ and $1 \mathrm{ml}$ $9.8 \mathrm{M} \mathrm{H}_{2} \mathrm{O}_{2}$ at $103^{\circ} \mathrm{C}$ for $2 \mathrm{~h}$. The particle diameter was measured by nanoparticle tracking analysis with the NanoSight LM 20 (NanoSight) using a previously described method [13]. This method tracks the brownian motion of nanoparticles in water using a laser and camera. The zeta potential of all of the samples was measured at the end of the deposition experiment with a ZetaSizer (nano series; Malvern Instruments) as an indication of the electrostatic stabilization against aggregation. As a measure for NOM, the dissolved organic carbon was measured by adding $\mathrm{HNO}_{3}$ and purging with $\mathrm{O}_{2}$ using a HiPerTOC total organic carbon analyzer (Thermo). The statistical calculations were performed in $\mathrm{R}$ (Ver 2.12.2) [23].

\section{RESULTS AND DISCUSSION}

The physicochemical parameters of the Rhine and Meuse water samples were similar. Natural colloids in the Rhine and Meuse water samples contained $12 \mathrm{mg} \mathrm{L}^{-1}$ and $5 \mathrm{mg} \mathrm{L}^{-1}$ of larger suspended solids and NOM consisted of $4.5 \mathrm{mg} \mathrm{L}^{-1}$ and $3.7 \mathrm{mg} \mathrm{L}^{-1}$ dissolved organic carbon, respectively (see Supplemental Data, Table S1).

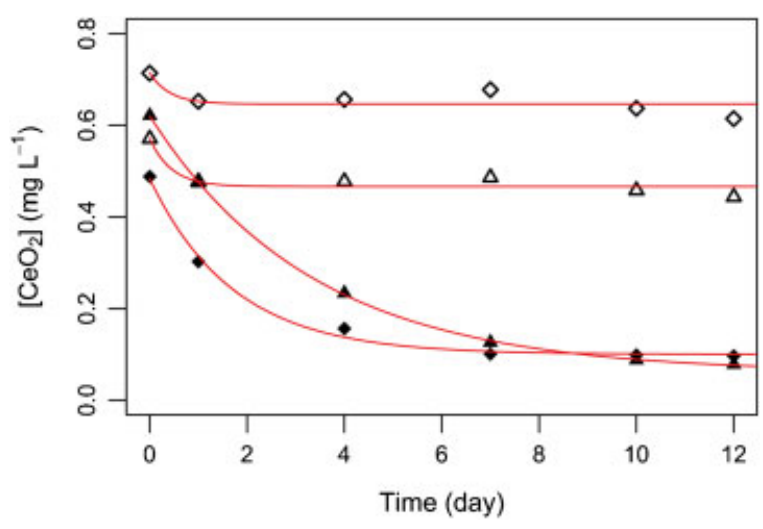

Fig. 2. The $\mathrm{CeO}_{2}$ nanoparticle sedimentation over time for the lowest initial concentration of $\mathrm{CeO}_{2}$ in the Rhine (triangles) and Meuse (diamonds) Rivers, The Netherlands. Water samples with natural colloids (solid symbols) show increased sedimentation compared to filtered river water (open symbols). The lines indicate least squares fit of Equation 2 to the data points $(N=6)$. [Color figure can be seen in the online version of this article, available at wileyonlinelibrary.com.]

For the most dilute sample $\left(1 \mathrm{mg} \mathrm{L}^{-1} \mathrm{CeO}_{2}\right)$, between 80 and $86 \%$ of $\mathrm{CeO}_{2}$ was removed in $12 \mathrm{~d}$ from the unfractionated river water, compared with a removal of only 14 to $22 \%$ from the filtered river water (Fig. 2). This can be explained by the $\mathrm{CeO}_{2}$ nanoparticle heteroaggregation with or deposition onto natural colloids, followed by sedimentation. However, it cannot be excluded that homoaggregation also plays a role prior to sedimentation at this $\mathrm{CeO}_{2}$ nanoparticle concentration. The natural colloids themselves settled out of suspension, as was confirmed by a decrease in the aluminum concentration from $454 \mu \mathrm{g} \mathrm{L}^{-1}$ to $15 \mu \mathrm{g} \mathrm{L}^{-1}$ and $69 \mu \mathrm{g} \mathrm{L}^{-1}$ to $8 \mu \mathrm{g} \mathrm{L}^{-1}$ after $10 \mathrm{~d}$ of sedimentation for the Rhine and Meuse water samples, respectively (Supplemental Data, Fig. S1). At the higher initial $\mathrm{CeO}_{2}$ concentrations (10 and $\left.100 \mathrm{mg} \mathrm{L}^{-1}\right)$, more than $99 \%$ of the $\mathrm{CeO}_{2}$ nanoparticles sedimented out of the unfiltered suspensions within $12 \mathrm{~d}$ of settling (Fig. 3). At these higher nanoparticle concentrations, homoaggregation was likely to be more important than interaction with the natural colloids. Although the residual concentration of $\mathrm{CeO}_{2}$ in the $10 \mathrm{mg} \mathrm{L}^{-1} \mathrm{CeO}_{2}$ suspension was still the lowest for the presence of natural colloids in both the Rhine and Meuse samples, more than $98 \%$ of the $\mathrm{CeO}_{2}$ nanoparticles sedimented out of the filtered river water (Fig. 3).

The $1 \mathrm{mg} \mathrm{L}^{-1} \mathrm{CeO}_{2}$ suspension in the filtered river water showed almost no sedimentation (Fig. 2). However, the zeta

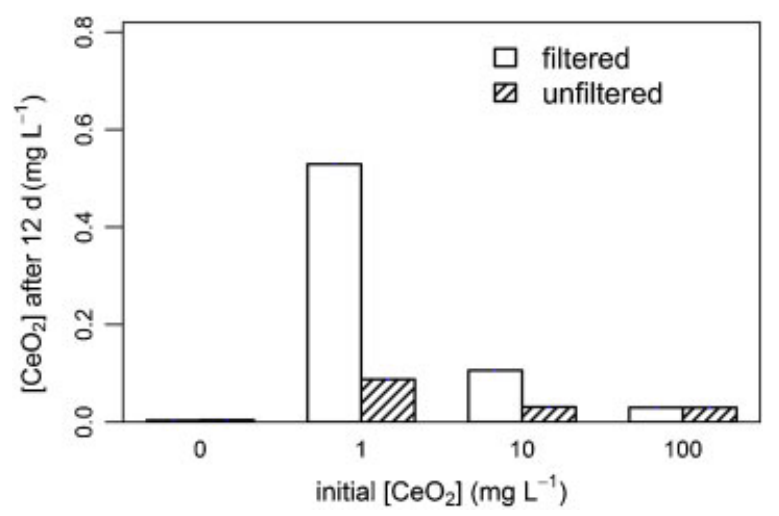

Fig. 3. Residual concentration of $\mathrm{CeO}_{2}$ nanoparticles after $12 \mathrm{~d}$ of settling in relation to the initial $\mathrm{CeO}_{2}$ concentration for filtered and unfiltered river water, average of concentration in Rhine and Meuse Rivers, The Netherlands. 
potential in relation to an electric conductivity of approximately $670 \mu \mathrm{sm}^{-1}$ of the river water was too low to explain this stability in terms of electrostatic repulsion, thereby suggesting steric repulsion resulting from the adsorbed NOM. The zeta potentials of colloids from the Rhine and Meuse samples and for both the 1 and the $10 \mathrm{mg} \mathrm{L}^{-1}$ suspensions were very similar (between -17.9 and $-15.4 \mathrm{mV}$ ). Only the $100 \mathrm{mg} \mathrm{L}^{-1}$ suspension showed a slightly less negative zeta potential (between -12.9 and $-11.5 \mathrm{mV}$ ). We suggest as an explanation that, in this case, the NOM fraction of natural colloids decreased the attachment efficiency of nanoparticles. At higher $\mathrm{CeO}_{2}$ nanoparticle concentration, this effect in filtered river water is not observed because of the limited amount of NOM available. Even though a relatively low sedimentation rate was measured, the particles in suspension were somewhat larger than the original material, ranging between 372 and $806 \mathrm{~nm}$ and between 387 and $519 \mathrm{~nm}$ for the Rhine and Meuse River water samples, respectively, compared with $171 \mathrm{~nm}$ for the stock $\mathrm{CeO}_{2}$ suspension.

The data showed that both the residual concentration $\left(\mathrm{C}_{\mathrm{res}}\right)$ and the rate of sedimentation $\left(k_{\mathrm{sed}}\right)$ were related to the initial nanoparticle concentration $\left(\mathrm{C}_{0}\right)$ or the collision frequency. This is known from colloid science theories describing aggregation and sedimentation [7,24,25]. Consistent with the theories, the results show that an increasing initial nanoparticle concentration resulted in an increasing rate of sedimentation [24] and a decreasing residual $\mathrm{CeO}_{2}$ nanoparticle concentration (Figs. 2 and 3 ). We reason that in addition to the collision frequency, the attachment efficiency also affected the aggregation rate. This is shown by the relatively stable suspension of $1 \mathrm{mg} \mathrm{L}^{-1} \mathrm{CeO}_{2}$ nanoparticles in filtered river water in the absence of suspended solids but in the presence of NOM. The NOM is known to reduce the attachment efficiency [24,26,27], although increases resulting from bridging have been reported at higher NOM concentrations [28,29]. As we have shown earlier [13], an increase in the NOM content can reduce the sedimentation rate for similar $\mathrm{CeO}_{2}$ nanoparticles. In general, the initial particle concentration, which affects the collision frequency, and the macromolecular components (e.g., the NOM), which affect the attachment efficiency, are the two main parameters affecting the aggregation and subsequent sedimentation of nanoparticles in water.

Homoaggregation is the dominant process when relatively high initial nanoparticle concentrations are present. The rate at which homoaggregation takes place is faster than what firstorder kinetics describes [7,25,30]. Conversely, when heteroaggregation is dominant, the following first-order kinetics apply

$$
\mathrm{dN}_{\mathrm{NP}} / \mathrm{dt}=-k_{\mathrm{agg}} \times \mathrm{N}_{\mathrm{NP}} \times \mathrm{N}_{\mathrm{NC}}\left[\mathrm{m}^{-3} \mathrm{~s}^{-1}\right],
$$

where $k_{\mathrm{agg}}\left[\mathrm{m}^{3} \mathrm{~s}^{-1}\right]$ is the aggregation rate constant. This model is commonly used for deposition in porous matrices [7,31]. Given the sedimentation process, we propose to use

$$
\mathrm{C}_{\mathrm{t}}=\left(\mathrm{C}_{0}-\mathrm{C}_{\text {res }}\right) \mathrm{e}^{\wedge}\left(-k_{\text {sed }} \cdot \mathrm{t}\right)+\mathrm{C}_{\text {res }}(\mathrm{mgL}-1)
$$

as a simplified model for estimating the concentration of nanoparticles over time. To test how this first-order model describes the measurements quantitatively, the model parameters $\mathrm{C}_{0}, \mathrm{C}_{\text {res }}$, and $k_{\text {sed }}$ were estimated by the nonlinear least squares regression (see Table 1). For this model, we assumed that heteroaggregation was the dominant process, which is the case at relatively low concentrations of nanoparticles. The model fit for the lowest initial particle concentration in the unfiltered river water was very good (Fig. 2); however, in the filtered river water, the residual concentration was already attained after the first day of settling. Thus, at relatively high initial particle concentrations, it is clear that the removal of particles from the suspension during the first day is faster than can be explained by first-order sedimentation kinetics, likely because of the increased homoaggregation at these higher nanoparticle concentrations. Consequently, the first measurement was omitted from the regression, because the model was not valid under those circumstances (Supplemental Data, Figs. S2 and S3). It should also be noted that the model describes the mass concentration of $\mathrm{CeO}_{2}$ nanoparticles in time. This means that the $\mathrm{CeO}_{2}$ nanoparticles in the residual concentration likely do not have the same physicochemical characteristics as the initially added nanoparticles. In time, nanoparticles are subject to changes in, for example, aggregate size and coating. This is the first experimental data demonstrating the effect of natural colloids on the rate of the removal of foreign nanoparticles from the water phase. According to our results using Rhine and Meuse water samples, the rate at which these particles disappear from the solution followed first-order kinetics and was strongly reduced by prefiltering, that is, the removal of the natural colloids. For the generalization to other nanoparticles and systems, the increased complexity of the natural environment should be kept in mind; for example, the increased shear stress or interaction with

Table 1. Nonlinear least-squares estimates of the sedimentation rate constant $\left(k_{\mathrm{sed}}\right)$, residual concentration $\left(\mathrm{C}_{\mathrm{res}}\right)$, and beginning

\begin{tabular}{|c|c|c|c|c|c|}
\hline & $\mathrm{C}_{0, \text { added }}\left(\mathrm{mg} \mathrm{L}^{-1}\right)$ & Natural colloids & $k\left(\mathrm{~d}^{-1}\right)$ & $\mathrm{C}_{\mathrm{res}}\left(\mathrm{mg} \mathrm{L}^{-1}\right)$ & $\mathrm{C}_{0}\left(\mathrm{mg} \mathrm{L}^{-1}\right)$ \\
\hline \multirow[t]{6}{*}{ Rhine } & 1 & $\mathrm{NC}$ & $0.30 \pm 0.007^{* * *}$ & $0.06 \pm 0.003^{* * *}$ & $0.62 \pm 0.003^{* * *}$ \\
\hline & & $\mathrm{F}$ & $2.24 \pm 1.91$ & $0.47 \pm 0.010^{* * *}$ & $0.57 \pm 0.019^{* * *}$ \\
\hline & $10^{\mathrm{b}}$ & $\mathrm{NC}$ & $0.83 \pm 0.040^{* *}$ & $0.05 \pm 0.005^{* *}$ & $2.10 \pm 0.083^{* *}$ \\
\hline & & $\mathrm{F}$ & $0.87 \pm 0.049^{* *}$ & $0.10 \pm 0.01^{* *}$ & $4.27 \pm 0.204^{* *}$ \\
\hline & $100^{\mathrm{b}}$ & $\mathrm{NC}$ & $0.98 \pm 0.006^{* * *}$ & $0.02 \pm 0.001^{* *}$ & $5.74 \pm 0.036^{* * *}$ \\
\hline & & $\mathrm{F}$ & $1.06 \pm 0.012^{* * *}$ & $0.02 \pm 0.002 *$ & $8.78 \pm 0.104^{* * *}$ \\
\hline \multirow[t]{6}{*}{ Meuse } & 1 & $\mathrm{NC}$ & $0.58 \pm 0.069^{* *}$ & $0.10 \pm 0.008^{* *}$ & $0.48 \pm 0.013^{* * *}$ \\
\hline & & $\mathrm{F}$ & $2.44 \pm 5.07$ & $0.65 \pm 0.014^{* * *}$ & $0.57 \pm 0.019^{* * *}$ \\
\hline & $10^{\mathrm{b}}$ & $\mathrm{NC}$ & $0.67 \pm 0.002^{* * *}$ & $0.02 \pm 0.0002^{* * *}$ & $0.68 \pm 0.001^{* * *}$ \\
\hline & & $\mathrm{F}$ & $0.79 \pm 0.010^{* * *}$ & $0.12 \pm 0.002^{* * *}$ & $2.89 \pm 0.028^{* * *}$ \\
\hline & $100^{\mathrm{b}}$ & $\mathrm{NC}$ & $0.99 \pm 0.052^{* *}$ & $0.05 \pm 0.016$ & $3.20 \pm 0.714^{*}$ \\
\hline & & $\mathrm{F}$ & $1.06 \pm 0.229^{*}$ & $0.05 \pm 0.010^{*}$ & $6.98 \pm 0.354^{* *}$ \\
\hline
\end{tabular}
concentration $\left(\mathrm{C}_{0}\right)$ for Equation $2^{\mathrm{a}}$

\footnotetext{
${ }^{a}$ Standard error and significance for $N=6$ samples in the fractionated (F) and unfractionated (NC) Rhine River and Meuse River water samples.

${ }^{\mathrm{b}} N=5$, concentration at $\mathrm{T}=0$ omitted from the regression due to the high concentration of $\mathrm{CeO}_{2}$.

* $p<0.05$.

*** $p<0.01$.

*** $p<0.001$.
} 
organisms [20,32]. We further propose that the model will adequately describe the clearance of nanoparticles from the water phase under various conditions. Low initial concentrations of nanoparticles are expected to be the most common, so the natural colloids present are likely to play an important role in nanomaterial sedimentation. The heteroaggregation with or the deposition onto these natural colloids, followed by their sedimentation from the water phase, is likely to be the main removal mechanism of nanoparticles in natural water. Therefore, this approach is a valuable observation for the future modeling of exposure concentrations of nanoparticles for the purpose of risk assessment.

\section{SUPPLEMENTAL DATA}

Figures S1-S3.

Table S1. (675 KB PDF).

Acknowledgement-We thank the Research and Development Department of The Netherlands Vaccine Institute for the use of the Malvern ZetaSizer, the Centre for Environmental Health Research at the National Institute for Public Health and the Environment (RIVM) for the use of the NanoSight LM 20, and Cornelis Miermans of the Laboratory for Environmental Monitoring at the RIVM for assisting with the inductively coupled plasma-mass spectroscopy measurements. This work was funded by the European Union Sixth Framework Program NanoInteract NMP4-CT-2006-033231 and the RIVM strategic research program SOR-S340030.

\section{REFERENCES}

1. Hendren CO, Mesnard X, Dröge J, Wiesner MR. 2011. Estimating production data for five engineered nanomaterials as a basis for exposure assessment. Environ Sci Technol 45:2562-2569.

2. Beaudrie CEH, Kandlikar M. 2011. Horses for courses: Risk information and decision making in the regulation of nanomaterials. J Nanopart Res 13:1477-1488.

3. Lin D, Tian X, Wu F, Xing B. 2010. Fate and transport of engineered nanomaterials in the environment. J Environ Qual 39:1896-1908.

4. Quik JTK, Vonk JA, Hansen SF, Baun A, Van De Meent D. 2011. How to assess exposure of aquatic organisms to manufactured nanoparticles? Environ Int 37:1068-1077.

5. Abbott LC, Maynard AD. 2010. Exposure assessment approaches for engineered nanomaterials. Risk Anal 30:1634-1644.

6. Hotze EM, Phenrat T, Lowry GV. 2010. Nanoparticle aggregation: Challenges to understanding transport and reactivity in the environment. J Environ Qual 39:1909-1924.

7. Petosa AR, Jaisi DP, Quevedo IR, Elimelech M, Tufenkji N. 2010. Aggregation and deposition of engineered nanomaterials in aquatic environments: Role of physicochemical interactions. Environ Sci Technol 44:6532-6549.

8. Lowry GV, Hotze EM, Bernhardt ES, Dionysiou DD, Pedersen JA, Wiesner MR, Xing B. 2010. Environmental occurrences, behavior, fate, and ecological effects of nanomaterials: An introduction to the special series. J Environ Qual 39:1867-1874.

9. Klaine SJ, Alvarez PJJ, Batley GE, Fernandes TF, Handy RD, Lyon DY, Mahendra S, McLaughlin MJ, Lead JR. 2008. Nanomaterials in the environment: Behavior, fate, bioavailability, and effects. Environ Toxicol Chem 27:1825-1851.

10. Buffle J, Wilkinson KJ, Stoll S, Filella M, Zhang JW. 1998. A generalized description of aquatic colloidal interactions: The three-colloidal component approach. Environ Sci Technol 32:2887-2899.

11. Hyung H, Fortner JD, Hughes JB, Kim JH. 2007. Natural organic matter stabilizes carbon nanotubes in the aqueous phase. Environ Sci Technol 41:179-184.

12. Yang K, Lin D, Xing B. 2009. Interactions of humic acid with nanosized inorganic oxides. Langmuir 25:3571-3576.
13. Quik JTK, Lynch I, Van Hoecke K, Miermans CJH, De Schamphelaere KAC, Janssen CR, Dawson KA, Cohen Stuart MA, Van De Meent D. 2010. Effect of natural organic matter on cerium dioxide nanoparticles settling in model fresh water. Chemosphere 81:711-715.

14. Thio BJR, Zhou D, Keller AA. 2011. Influence of natural organic matter on the aggregation and deposition of titanium dioxide nanoparticles. J Hazard Mater 189:556-563.

15. Chen KL, Elimelech M. 2007. Influence of humic acid on the aggregation kinetics of fullerene (C-60) nanoparticles in monovalent and divalent electrolyte solutions. J Colloid Interface Sci 309:126-134.

16. Ferry JL, Craig P, Hexel C, Sisco P, Frey R, Pennington PL, Fulton MH, Scott IG, Decho AW, Kashiwada S, Murphy CJ, Shaw TJ. 2009. Transfer of gold nanoparticles from the water column to the estuarine food web. Nat Nano 4:441-444.

17. Battin TJ, Kammer Fvd, Weilhartner A, Ottofuelling S, Hofmann T 2009. Nanostructured $\mathrm{TiO}_{2}$ : Transport behavior and effects on aquatic microbial communities under environmental conditions. Environ Sci Technol 43:8098-8104.

18. Kiser MA, Ryu H, Jang H, Hristovski K, Westerhoff P. 2010. Biosorption of nanoparticles to heterotrophic wastewater biomass. Water Res 44: 4105-4114.

19. Limbach LK, Bereiter R, Mueller E, Krebs R, Gaelli R, Stark WJ. 2008 Removal of oxide nanoparticles in a model wastewater treatment plant: Influence of agglomeration and surfactants on clearing efficiency. Environ Sci Technol 42:5828-5833.

20. Van Hoecke K, Quik JTK, Mankiewicz-Boczek J, De Schamphelaere KAC, Elsaesser A, Van der Meeren P, Barnes C, McKerr G, Howard CV, Van De Meent D, Rydzyninski K, Dawson KA, Salvati A, Lesniak A, Lynch I, Silversmit G, De Samber B, Vincze L, Janssen CR. 2009. Fate and effects of $\mathrm{CeO}_{2}$ nanoparticles in aquatic ecotoxicity tests. Environ Sci Technol 43:4537-4546.

21. De Faria LA, Trasatti S. 1994. The point of zero charge of $\mathrm{CeO}_{2}$.J Colloid Interface Sci 167:352-357.

22. Monitoring Programme of the National Water Systems. 2008. Waterbase, Monitoring Programme of the National Water Systems. The National Institute for Coastal and Marine Management, The Hague, The Netherlands.

23. R development Core Team and Contributors Worldwide. 2011. The $\mathrm{R}$ Stats Package. Ver 2.12.0. R Foundation for Statistical Computing. Vienna, Austria.

24. Keller AA, Wang H, Zhou D, Lenihan HS, Cherr G, Cardinale BJ, Miller R, Ji Z. 2010. Stability and aggregation of metal oxide nanoparticles in natural aqueous matrices. Environ Sci Technol 44:1962-1967.

25. Arvidsson R, Molander S, Sandén BA, Hassellov M. 2011. Challenges in exposure modeling of nanoparticles in aquatic environments. Hum Ecol Risk Assess 17:245-262.

26. Zhang Y, Chen Y, Westerhoff P, Crittenden J. 2009. Impact of natural organic matter and divalent cations on the stability of aqueous nanoparticles. Water Res 43:4249-4257.

27. Saleh NB, Pfefferle LD, Elimelech M. 2010. Influence of biomacromolecules and humic acid on the aggregation kinetics of single-walled carbon nanotubes. Environ Sci Technol 44:2412-2418.

28. Abe T, Kobayashi S, Kobayashi M. 2011. Aggregation of colloidal silica particles in the presence of fulvic acid, humic acid, or alginate: Effects of ionic composition. Colloids Surf Physicochem Eng Aspects 379:21-26.

29. Liu X, Wazne M, Han Y, Christodoulatos C, Jasinkiewicz KL. 2010 Effects of natural organic matter on aggregation kinetics of boron nanoparticles in monovalent and divalent electrolytes. J Colloid Interface Sci 348:101-107.

30. von Smoluchowski M. 1918. Versuch einer mathematischen Theorie der Koagulationskinetik kolloider Lösungen. Z Phys Chem 92:129-168.

31. Kretzschmar R, Barmettler K, Grolimund D, Yan Y-D, Borkovec M, Sticher H. 1997. Experimental determination of colloid deposition rates and collision efficiencies in natural porous media. Water Resources 33:1129-1137.

32. Baun A, Sørensen SN, Rasmussen RF, Hartmann NB, Koch CB. 2008 Toxicity and bioaccumulation of xenobiotic organic compounds in the presence of aqueous suspensions of aggregates of nano-C60. Aquat Toxicol 86:379-387. 